Original Research

\title{
The impact of anxiety level on decision to seek medical care of non-COVID cardiac patients during the pandemic outbreak - single-center experience in Israel
}

\author{
Ofir Koren ${ }^{1,2}$,*, Saleem Abu Rajab ${ }^{3}$, Mohammad Barbour ${ }^{1}$, Moriah Shachar ${ }^{4}$, Amit Shahar ${ }^{5}$, \\ Khaled Zubidat $^{6}$, Wasim Slim ${ }^{6}$, Daher Igbariya ${ }^{6}$, Ehud Rozner ${ }^{1}$, Yoav Turgeman ${ }^{1,2}$, \\ Robert Naami ${ }^{7}$, Vivek Patel ${ }^{7}$, Edmund Naami ${ }^{5}$, Einat Mader ${ }^{2,8}$ \\ ${ }^{1}$ Heart Institute, Emek Medical Center, 1834111 Afula, Israel \\ ${ }^{2}$ Bruce Rappaport Faculty of Medicine, Technion Israel Institute of Technology, 3525433 Haifa, Israel \\ ${ }^{3}$ Internal Medicine C, Emek Medical Center, 1834111 Afula, Israel \\ ${ }^{4}$ The Azrieli Faculty of Medicine, Bar-Ilan University, 1311502 Zefat, Israel \\ ${ }^{5}$ University of Illinois College of Medicine, Chicago, IL 60612, USA \\ ${ }^{6}$ Emergency Department, Emek Medical Center, 1834111 Afula, Israel \\ ${ }^{7}$ Cedars-Sinai Medical Center, Smidt Heart Institute, Los Angeles, CA 90048, USA \\ ${ }^{8}$ Med-Psych Service, Emek Medical Center, 1834111 Afula, Israel \\ *Correspondence: Drkorenofir@gmail.com (Ofir Koren) \\ Academic Editor: Alpo Vuorio \\ Submitted: 22 November 2021 Revised: 13 January 2022 Accepted: 17 January 2022 Published: 8 February 2022
}

\begin{abstract}
Background: Coronavirus disease 2019 (COVID-19) has significantly the delivery of healthcare all around the world. In part, an abnormal and unexplained high non-COVID-related cardiovascular mortality rate was reported during the outbreak. We assess the correlation between anxiety level and decision to seek medical care (DSMC) during the COVID-19 pandemic. Materials and methods: We recruited patients with cardiovascular complaints admitted to the emergency department in a single institute in Israel between February and September 2020. Anxiety level was measured using available questionnaires. DSMC was assessed with a newly designed questionnaire (DM-19). Results: Two-hundreds seventy patients were included in the study. The mean age was $52.6 \pm 14.9$ (females represent 36.2\%). $23.6 \%$ of the patients had at least moderate cardiovascular risk. High anxiety levels were (HAL) reported in nearly half of the patients (57.1\% and 49.8\% for General Anxiety Disorder Assessment [GAD-7] and Beck Anxiety Inventory [BAI], respectively). It was more prevalent in old, married, and unemployed patients (significant $p$-value for all in both questionnaires). Age was an independent factor $\left(\chi^{2}=6.33, p<0.001\right.$, odds-ratio: 4.8$)$ and had a positive correlation on anxiety level $(\mathrm{r}=0.81, p<0.001$ and $\mathrm{r}=0.62, p<0.001$, for GAD-7 and BAI, respectively). The DM-19 revealed a strong and positive correlation of seeking medical care with anxiety level ( $\mathrm{R}^{2}$ linear $=0.44, \mathrm{r}=0.70, p<0.001$ and $\mathrm{R}^{2}$ linear $=0.30, \mathrm{r}=0.58, p<0.001$ for GAD-7 and BAI, respectively) and results in deferring medical care for several days than patient with low anxiety level $(p=0.02)$. Conclusions: We observed an abnormal prevalence of a high level of anxiety among non-COVID patients with cardiovascular complaints, which affected the patient's likelihood to seek medical care and resulted in an unreasonable postponement of medical treatment. Our results may explain cardiovascular mortality trends during the outbreak and should be considered in health crisis management. Future studies will involve multi-institutional efforts to address reproducibility of our findings across geographic regions in the state of the global impact. Additionally, it is imperative to understand the effects of the coronavirus vaccine on patient consideration to seek medical care.
\end{abstract}

Keywords: anxiety; chest pain; COVID-19; decision to seek medical care; cardiovascular diseases; outbreak

\section{Introduction}

The unpredictable nature of the 2019-2020 Coronavirus pandemic has been shown to substantially increase the reported mental health disorders [1-7].

The social distancing, isolation, lack of familial support, inactivity, temporary or indefinite employment termination, loss of income, and personal autonomy have led to detrimental effects on both physical and mental status in both previously healthy people and those with preexisting conditions $[8,9]$.

Anxiety and depression were the most prevalent psy- chological disorders reported during the COVID-19 outbreak [10]. Anxiety is an emotional state characterized by feelings of tension, anxious thought, and apprehension [11]. High anxiety level (HAL) has been shown to affect behavior by avoiding coping, social strategy, and situation [12-14].

Decision-making is a cognitive behavior of selecting a course of action among various possible alternatives. It is commonly influenced by values, preferences, beliefs, knowledge, and situations and could be rational or irrational [15-18]. Therefore, the decision to seek medical care can be particularly complex given the inherent nature 
of preserving one's health and welfare. Previous studies demonstrate how variability in the population can affect decisions to seek medical care. Commonly cited factors include provider proximity, socioeconomic status, health insurance, and preexisting illness knowledge. Specifically, individuals who have dealt with an illness in the past and been informed by an educated provider are more knowledgeable, sensitized, and fearful of possible signs of relapse or worsening of their conditions [19-23].

Moreover, individuals living with a partner were more likely to seek health care than singles. One explanation for this is that discussing symptoms or concerns may prompt one's partner to seek health care. Demographics also play a major role where women and elderly individuals, albeit without disabilities, are more likely to seek care. Nevertheless, the correlation between anxiety level and the decision to seek medical care during the outbreak is lacking [24-26].

The impact of COVID-19 on mental health disorders has been demonstrated in large and worldwide cohort studies. The initial reports of the outbreak in the news and the social media platforms lead to a disturbing increase in anxiety due to psychological and physical stressors, fear of contracting the disease, concerns for financial consequences, life routine disruption, and more [1-8].

The outbreak has created an enormous global challenge for all health maintenance organizations (HMOs). Hospitals, intensive care units, and internal wards were converted into treating mainly COVID patients. The general lockdown, HMO reorganization, and the tremendous restrictions on the general population, medical care providers, and the general population's mental state had a substantial and direct influence on the medical admission rate [27-31].

\section{Study rationale}

The study's goal was to examine whether the COVID19 outbreak affected the level of stress and anxiety among patients who sought medical care due to cardiovascularrelated complaints and whether it impacted their decision to do so.

\section{Summary}

Our single-center study explores the prevalence and impact of anxiety among cardiac patients arriving to the emergency department in the initial COVID-19 outbreak. We demonstrate how high anxiety levels substantially impact patients' decisions to seek medical care. Our results may explain cardiovascular mortality trends during the outbreak and should be considered in health crisis management.

\section{Materials and methods}

\subsection{Data collection}

We designed a cross-sectional survey-based prospective cohort study conducted in the Cardiology Department at Emek Medical Center in Israel in collaboration with the Med-Psych service and the Emergency Department. Patient recruitment began in February 2020 and lasted until September 2020. The study population included patients admitted to the Emergency Department with a cardiovascular complaint. Patients were excluded from the study if they were younger than 18 , mentally disabled, pregnant, or tested positive for COVID-19 infection. Patients were recruited only after complete triage screening and preliminary medical examination to exclude urgent scenarios. Supplemental data on demographics, clinical data, and medical history were obtained using computerized medical records (“Orion", "Ofek", and "Chameleon”).

\subsection{Questionnaires}

Patients were instructed to independently complete four questionnaires written in Israel's four most used languages (Hebrew, Arabic, Russian, and English): The Beck Anxiety Inventory, the Cardiac Anxiety Questionnaire, and the General Anxiety Questionnaire.

The Generalized Anxiety Disorder Assessment (GAD-7) is a seven-item self-assessment questionnaire used to assess the severity of generalized anxiety disorder (GAD). The GAD-7 score is calculated by assigning 0-3 for each of the seven questions and obtaining a sum score between 0 to 21 . Scores of 5, 10, and 15 are taken as the cutoff points for mild, moderate, and severe anxiety, respectively. Using a threshold score of 10, the GAD-7 has a sensitivity of $89 \%$ and a specificity of $82 \%$ for detecting high anxiety levels requiring further workup. The Beck Anxiety Inventory (BAI) is a 21 self-assessment multiple-choice question used to measure the severity of anxiety among adults. The standardized cutoffs are $0-7$, 8-15, 16-25, and 26-63 for minimal, mild, moderate, and severe anxiety, respectively [24-26].

We designed a fourth self-assessment questionnaire (DM-19 questionnaire, Supplementary Table 1) to assess whether the patient considered COVID-19 before seeking medical treatment.

The DM-19 questionnaire contains two parts: the first is a nine-item multiple-choice survey designed to assess the importance of COVID-19 in patients' daily decisions and assess decision-making concerns before seeking medical care. It contains five 'Yes', 'No' and 'Do not know' answers and four common escalating scale questions (i.e., extremely worried, worried, and do not worry). In the second part, the patients were instructed to choose three out of 12 sentences best describing their concerns before seeking medical care to assess the importance of concerns. For analysis purposes, we clustered these sentences into four clusters: regulations-related, illness-driven, non-illnessrelated, and financial-driven concern (Supplementary Table 2). Patients who did not fulfill at least $30 \%$ of the questionnaire were excluded from the analysis. 


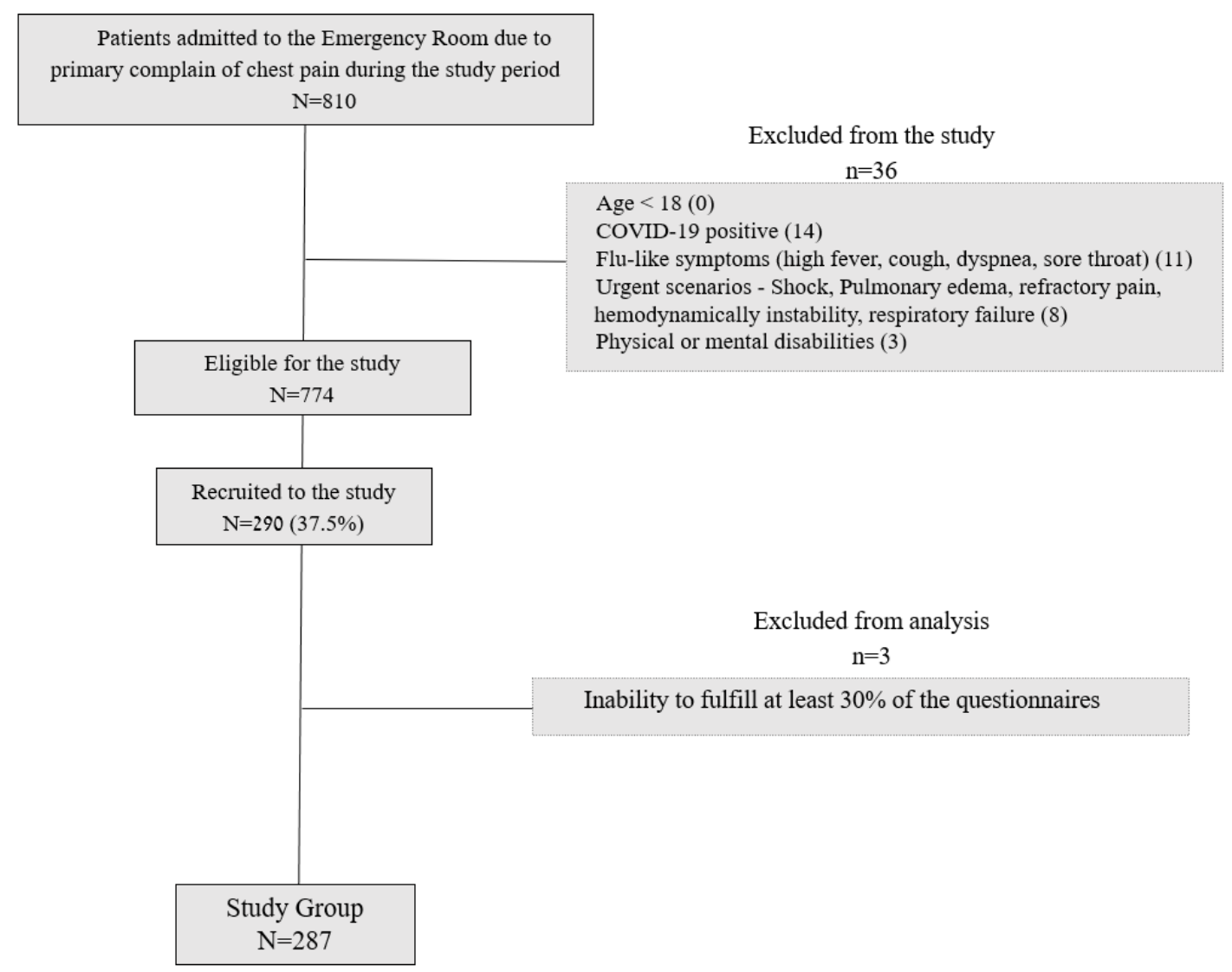

Fig. 1. Criteria determining eligibility. Patients admitted to Emek medical center with cardiovascular complaints were assessed for inclusion criteria and subsequently recruited to this study.

Patients' medical information regarding essential characteristics and occupational and marital status were collected from the Clalit health data system (Orion, Ofek, and Chameleon software; Tel Aviv, Israel).

\subsection{Ethics approval and consent to participate}

The Ethics Committee approved the study of the hospital following the Helsinki Convention (Approval No. EMC-20-0057). All subjects gave their informed consent for inclusion before they participated in the study. Recruitment was performed within 24-48 hours of hospital arrival after obtaining informed consent. Eligible patients underwent a personal interview during which they were asked to answer a structured self-assessment questionnaire written in their native language.

\subsection{Sample size}

Calculation of the sample size was based on three main criteria: the population size - the total number of patients who were admitted to the emergency department during the study period due to chest pain (estimated as 840 patients), an estimated recruitment rate of about 0.3 and a response distribution of $50 \%$. To achieve a margin of error of $5 \%$ and a $95 \%$ confidence level, we needed to recruit at least 264 patients.

\subsection{Statistics}

A chi-square test was performed to analyze the association between the questionnaires and categorical variables. For continuous variables, we used the $t$-test (alternatively, the Wilcoxon two-sample test). Categorical variables were presented using frequencies and percentages. Means and standard deviations were calculated for continuous data, while frequencies and percentages were used for categorical data. $95 \%$ confidence intervals were calculated for key admission characteristics. Pearson correlation test was performed to test the association and the correlation between BAI and GAD-7 and the DM-19 to the rest of the questionnaires. Differences considered statistically significant were at the 2 -sided $p$-value of 0.05 . Statistical analysis was performed using SPSS version 24 (IBM, Chicago, IL, USA).

\section{Results}

During the study period, 810 patients were admitted to the Emergency Department with cardiovascular complaints. Thirty-six patients did not meet the inclusion criteria (Age $<18$, COVID-19 positive, flu-like symptoms, urgent scenarios such as shock, pulmonary edema, refractory pain, respiratory failure, and physical or mental disability). Seven hundred seventy-four patients were eligible for the study. We succeeded in recruiting 290 patients $(37.5 \%$ re- 

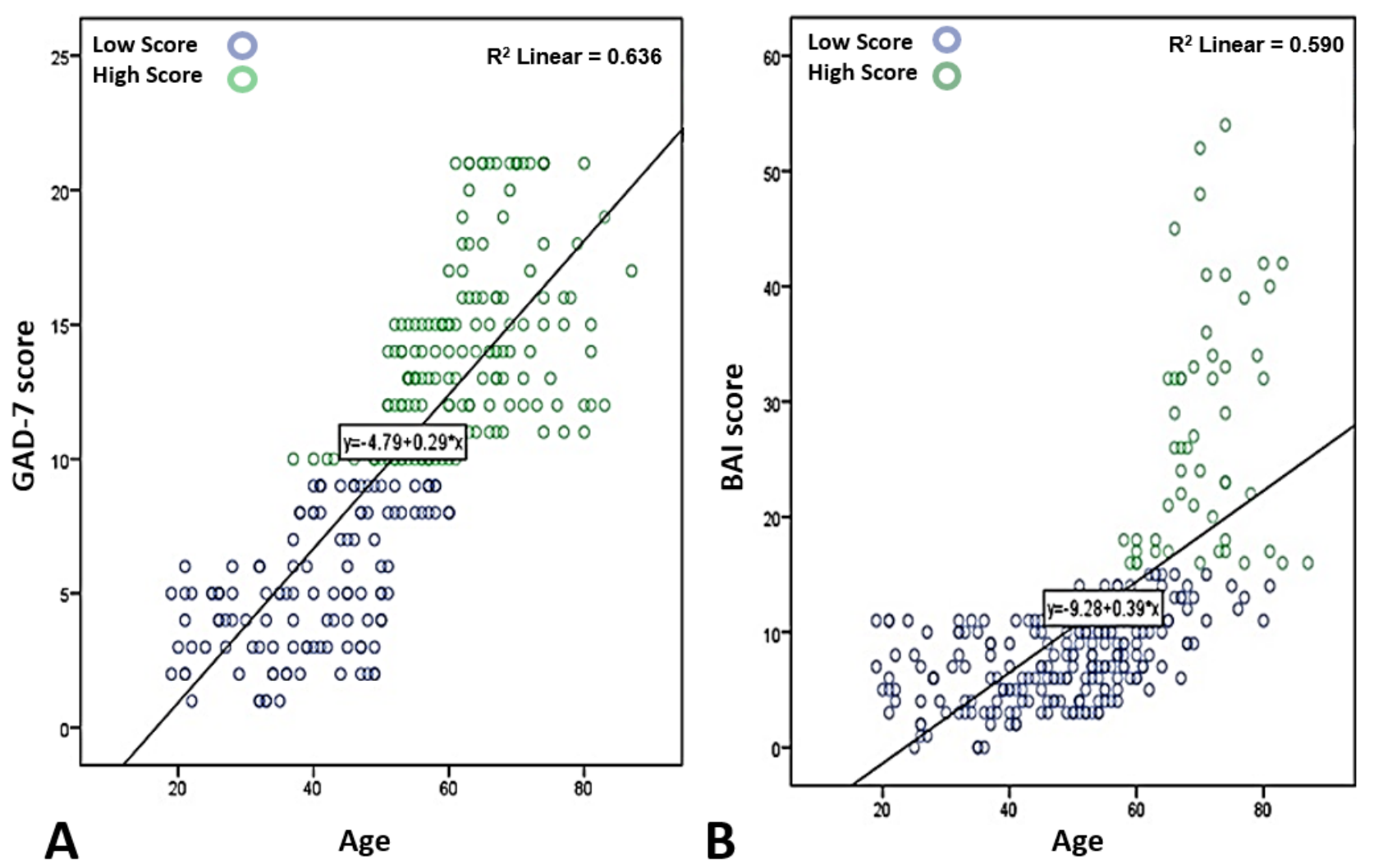

Fig. 2. Correlation between age and anxiety level. (A) Anxiety assessed byGAD-7 questionnaire; (B) anxiety assessed by the BAI (B) questionnaire.

cruit rate). Three patients were excluded from the analysis due to the inability to fulfill at least $30 \%$ of the questionnaires. The study population included 287 patients (Fig. 1).

Two hundred eighty-seven patients participated in the study. The total participants' mean age was $52.6 \pm 14.9$ (19-87), and 183 (63.8\%) patients were males. High anxiety levels were reported in nearly half of the patients $(57.1 \%$ and $49.8 \%$ for GAD-7 and BAI, respectively).

The mean anxiety level was $10.3 \pm 5.3(1-21)$ and $16.5 \pm 9.4(0-54)$ for GAD-7 and BAI. To measure and analyze HAL, we used a validated cutoff score of $\geq 10$ in the GAD-7 questionnaire and a cutoff score of $\geq 26$ in the BAI questionnaire.

Age was found to be a strong independent factor $\left(\chi^{2}\right.$ $=6.33, p<0.001$, OR: 4.8$)$ and had a positive correlation with high anxiety level $(\mathrm{r}=0.81, p<0.001$ and $\mathrm{r}=0.62$, $p<0.001$, for GAD-7 and BAI, respectively) in all questionnaires. Married and unemployed patients with multiple cardiovascular risk factors were at particularly high risk for high anxiety levels $(0.01$, and 0.04 for matched patients, $p$ $<0.001$ for employed patients, and $p<0.001$ for comorbidities GAD-7, and BAI, respectively). Patients who had a history of anxiety, depression, or psychiatric disease were at particular risk of having high anxiety levels $(p<0.001$ for all). Ethnicity was not associated with anxiety levels (Table 1, Fig. 2).
The most common initial presentation was chest pain seen in more than eighty percent of patients regardless of anxiety level. HAL patients were diagnosed more commonly with unstable angina and Non-ST elevation myocardial infarction and had a higher rate of coronary catheterization (significant $p$-value for all). Nevertheless, the diagnosis of coronary artery disease (defined as $>50 \%$ stenosis of the left main stem, $>70 \%$ stenosis in a major coronary vessel, or $<70 \%$ stenosis with fractional flow reserve $\leq 0.8$ ) [20] was significantly lower in HAL patients as compared to low anxiety levels (LAL) patients $(58.5 \%$ vs. $78.6 \%$, and $52.6 \%$ vs. $72.0 \%$, for HAL vs. LAL in GAD-7 and BAI, respectively, $p<0.001$ for all) (Table 2 ).

\section{DM-19 questionnaire design and analysis}

Two hundred eighty-seven patients completed the DM-19 questionnaire. We weighted the answers of the DM19 based on its impact on the decision to seek medical care. Answers were weighted +1 or +2 if the pandemic significantly impacted the decision before seeking medical care; ' 0 ' if the pandemic had some level of concern but did not alter the normal medical decision to seek care as before the outbreak, and ' -1 ' if the pandemic was not a concern when seeking medical care. Three questions weighted ' 2 ' points due to the answers' direct nature and their impact on decision-making (Supplementary Table 1). The scores ranged from -8 to 12 . Analyzing all possibilities yield the 
Table 1. Patients' baseline characteristics according to the level of anxiety based on the GAD-7, and BAI questionnaires.

\begin{tabular}{|c|c|c|c|c|c|c|}
\hline \multirow{3}{*}{ Patient's characteristics } & \multicolumn{2}{|c|}{ GAD-7 } & \multirow{3}{*}{$p$-value } & \multicolumn{2}{|c|}{ BAI } & \multirow{3}{*}{$p$-value } \\
\hline & \multirow{2}{*}{$\begin{array}{c}\text { Low score }<10 \\
\mathrm{~N}=123\end{array}$} & \multirow{2}{*}{$\begin{array}{c}\text { High score } \geq 10 \\
\mathrm{~N}=164\end{array}$} & & \multirow{2}{*}{$\begin{array}{c}\text { Low score }<26 \\
\mathrm{~N}=144\end{array}$} & \multirow{2}{*}{$\begin{array}{c}\text { High score } \geq 26 \\
N=143\end{array}$} & \\
\hline & & & & & & \\
\hline Age Mean $\pm \mathrm{SD}$, (Range) & $39.9 \pm 10.7(19-60)$ & $62.28 \pm 9.3(37-87)$ & $<0.001$ & $45.4 \pm 12.2(19-81)$ & $59.9 \pm 13.8(19-87)$ & $<0.001$ \\
\hline Gender (Male) & $79(64.2 \%)$ & $104(63.4 \%)$ & 0.88 & $95(66.0 \%)$ & $88(61.5 \%)$ & 0.43 \\
\hline \multicolumn{7}{|l|}{ Marital status } \\
\hline Married & $103(83.7 \%)$ & $153(93.3 \%)$ & \multirow{3}{*}{0.01} & $118(81.9 \%)$ & $138(96.5 \%)$ & \multirow{3}{*}{0.04} \\
\hline Single & $19(15.4 \%)$ & $6(3.7 \%)$ & & $16(11.1 \%)$ & $9(6.3 \%)$ & \\
\hline Divorce & $1(0.8 \%)$ & $5(3.0 \%)$ & & $3(2.1 \%)$ & $3(2.1 \%)$ & \\
\hline Employed & $79(64.2 \%)$ & $104(63.4 \%)$ & 0.88 & $95(66.0 \%)$ & $88(61.5 \%)$ & 0.43 \\
\hline \multicolumn{7}{|l|}{ Ethnic group } \\
\hline Arabs & $53(43.1 \%)$ & $75(45.7 \%)$ & \multirow{4}{*}{0.29} & $68(47.2 \%)$ & $60(42.0 \%)$ & \multirow{4}{*}{0.49} \\
\hline Jews (Israeli Born) & $35(28.5 \%)$ & $50(30.5 \%)$ & & $38(26.4 \%)$ & $47(32.9 \%)$ & \\
\hline Jews (Former USSR) & $30(24.4 \%)$ & $27(16.5 \%)$ & & $31(21.5 \%)$ & $26(18.2 \%)$ & \\
\hline Jews (African Born) & $5(4.1 \%)$ & $12(7.3 \%)$ & & $7(4.9 \%)$ & $10(7.0 \%)$ & \\
\hline Smoker & $52(42.3 \%)$ & $80(48.8 \%)$ & 0.27 & $65(45.1 \%)$ & $67(46.9 \%)$ & 0.77 \\
\hline Obesity & $42(34.1 \%)$ & $75(45.7 \%)$ & 0.04 & $56(38.9 \%)$ & $61(42.7 \%)$ & 0.51 \\
\hline Family history of IHD & $37(30.1 \%)$ & $56(34.1 \%)$ & 0.46 & $49(34.0 \%)$ & $44(30.8 \%)$ & 0.55 \\
\hline Hypertension & $33(26.8 \%)$ & $115(70.1 \%)$ & $<0.001$ & $53(36.8 \%)$ & $95(66.4 \%)$ & $<0.001$ \\
\hline Hyperlipidemia & $40(32.5 \%)$ & $116(70.7 \%)$ & $<0.001$ & $64(44.4 \%)$ & $92(64.3 \%)$ & 0.001 \\
\hline Diabetes mellitus & $15(12.2 \%)$ & $76(46.3 \%)$ & $<0.001$ & $29(20.1 \%)$ & $62(43.4 \%)$ & $<0.001$ \\
\hline CABG & $3(2.4 \%)$ & $11(6.7 \%)$ & 0.09 & $6(4.2 \%)$ & $8(5.6 \%)$ & 0.57 \\
\hline Atrial fibrillation & $3(2.4 \%)$ & $22(13.4 \%)$ & 0.001 & $8(5.6 \%)$ & $17(11.9 \%)$ & 0.04 \\
\hline IHD & $12(9.8 \%)$ & $70(42.7 \%)$ & $<0.001$ & $27(18.8 \%)$ & $55(38.5 \%)$ & $<0.001$ \\
\hline Heart failure & $5(4.1 \%)$ & $22(13.4 \%)$ & 0.007 & $12(8.3 \%)$ & $15(10.5 \%)$ & 0.52 \\
\hline CVA/TIA & $8(6.5 \%)$ & $24(14.6 \%)$ & 0.03 & $15(10.4 \%)$ & $17(11.9 \%)$ & 0.69 \\
\hline Anxiety & $21(17.1 \%)$ & $63(38.4 \%)$ & $<0.001$ & $26(18.1 \%)$ & $58(40.6 \%)$ & $<0.001$ \\
\hline Depression & $9(7.3 \%)$ & $36(22 \%)$ & 0.001 & $10(6.9 \%)$ & $35(24.5 \%)$ & $<0.001$ \\
\hline Psychiatric disease & $11(8.9 \%)$ & $52(31.7 \%)$ & $<0.001$ & $18(12.5 \%)$ & $45(31.5 \%)$ & $<0.001$ \\
\hline
\end{tabular}

CABG, Coronary artery bypass graft surgery; IHD, Ischemic heart disease; USSR, Union of Soviet Socialist Republics; CVA, Cerebrovascular accident; TIA, Transient ischemic attack.

following results: scores between -8 and 5 suggest the outbreak did not influence the decision to seek medical care, scores between 5 and 7 indicate the outbreak had been part of the patient's concerns before seeking medical care, and a score of 8 or higher imply that the decision to seek medical care was significantly affected by the outbreak.

Based on score interpretation of the DM-19, fifty-five (19.2\%) patients had a score of less than 5, and $232(80.8 \%)$ patients had a score of five or greater. The mean score of the total study population was $6.4 \pm 2.6(7.0,-4-11)$. The mean score of the patients in the DM-19 questionnaire who reported that the pandemic influenced their decision to seek medical care was $7.15 \pm 1.5(7.0,5-11)$, where the mean score of patients who reported no relation of the outbreak with their decision to seek medical care was $2.4 \pm 2.11$ (3.0, $-4-4)$.

The total score on the DM questionnaire showed a positive correlation with the categorized anxiety level of GAD-
7 and the BAI questionnaires $\left(\mathrm{R}^{2}\right.$ linear $=0.44, \mathrm{r}=0.70, p$ $<0.001$ and $\mathrm{R}^{2}$ linear $=0.30, \mathrm{r}=0.58, p<0.001$ for GAD7 and BAI, respectively), indicating that patients who had high DSMC score also exhibit high anxiety level (Fig. 3).

Moreover, question analysis of the DM-19 reveals a connection between anxiety and the time to seek medical care. Most HAL patients sought medical care more than two days from symptoms onset, whereas most LAL patients sought medical care on the same day of symptoms onset (Fig. 3).

Analyzing the patient's concern of coming to the hospital regarding anxiety level showed different distribution graphs. Non-illness-driven concern was the most prominent among HAL patients in both questionnaires. Illnessrelated concerns and losing financial support were the most prominent among LAL patients in both questionnaires (Fig. 4). 
Table 2. Patients' cardiovascular assessment according to the level of anxiety based on the GAD-7 and the BAI questionnaires.

\begin{tabular}{|c|c|c|c|c|c|c|}
\hline \multirow{3}{*}{ Patient characteristics } & \multicolumn{3}{|c|}{ GAD-7 } & \multicolumn{3}{|c|}{ BAI } \\
\hline & \multicolumn{2}{|c|}{ Low score $<10$ High score $\geq 10$} & \multirow{2}{*}{$p$-value } & \multicolumn{2}{|c|}{ Low score $<26$ High score $\geq 26$} & \multirow{2}{*}{$p$-value } \\
\hline & $\mathrm{N}=123$ & $N=164$ & & $\mathrm{~N}=144$ & $\mathrm{~N}=143$ & \\
\hline \multicolumn{7}{|l|}{ Primary complains } \\
\hline Chest pain & $106(86.2 \%)$ & $141(86.0 \%)$ & \multirow{4}{*}{0.61} & $124(86.1 \%)$ & $123(86.0 \%)$ & \multirow{4}{*}{0.63} \\
\hline Dyspnea & $6(4.9 \%)$ & $11(6.7 \%)$ & & $7(4.9 \%)$ & $10(7.0 \%)$ & \\
\hline Palpitation & $10(8.1 \%)$ & $12(7.3 \%)$ & & $12(8.3 \%)$ & $10(7.0 \%)$ & \\
\hline Other & $1(0.8 \%)$ & $0(0.0)$ & & $1(0.7 \%)$ & $0(0.0)$ & \\
\hline ECG changes on admission & $8(6.5 \%)$ & $29(17.7 \%)$ & 0.005 & $11(7.6 \%)$ & $26(18.2 \%)$ & 0.008 \\
\hline High serum troponin I & $8(6.5 \%)$ & $24(14.6 \%)$ & 0.03 & $11(7.6 \%)$ & $21(14.7 \%)$ & 0.04 \\
\hline High serum CPK level & $8(6.5 \%)$ & $23(14.0 \%)$ & 0.04 & $11(7.6 \%)$ & $20(14.0 \%)$ & 0.05 \\
\hline \multicolumn{7}{|l|}{ Preliminary diagnosis } \\
\hline Stable angina & $6(4.9 \%)$ & $29(17.7 \%)$ & & $8(5.6 \%)$ & $33(23.1 \%)$ & \\
\hline Unstable angina/NSTEMI & $9(7.3 \%)$ & $24(14.6 \%)$ & 0.002 & $11(7.6 \%)$ & $24(16.8 \%)$ & $<0.001$ \\
\hline Myocarditis & $3(2.4 \%)$ & $2(1.2 \%)$ & & $4(2.8 \%)$ & $1(0.7 \%)$ & \\
\hline Coronary catheterization & $14(11.4 \%)$ & $67(40.9 \%)$ & $<0.001$ & $22(15.3 \%)$ & $59(41.3 \%)$ & $<0.001$ \\
\hline $\begin{array}{l}\text { Significant lesion (per CAQ } \\
\text { group/per coronary catheterization) }\end{array}$ & $11(8.9 / 78.6)$ & $38(23.2 / 58.5)$ & $0.002 /<0.001$ & $18(12.5 / 72.0)$ & $31(21.6 / 52.5)$ & $0.03 /<0.001$ \\
\hline
\end{tabular}

ECG, electrocardiogram; CPK, creatine phosphokinase; NSTEMI, non-ST elevation myocardial infarction.
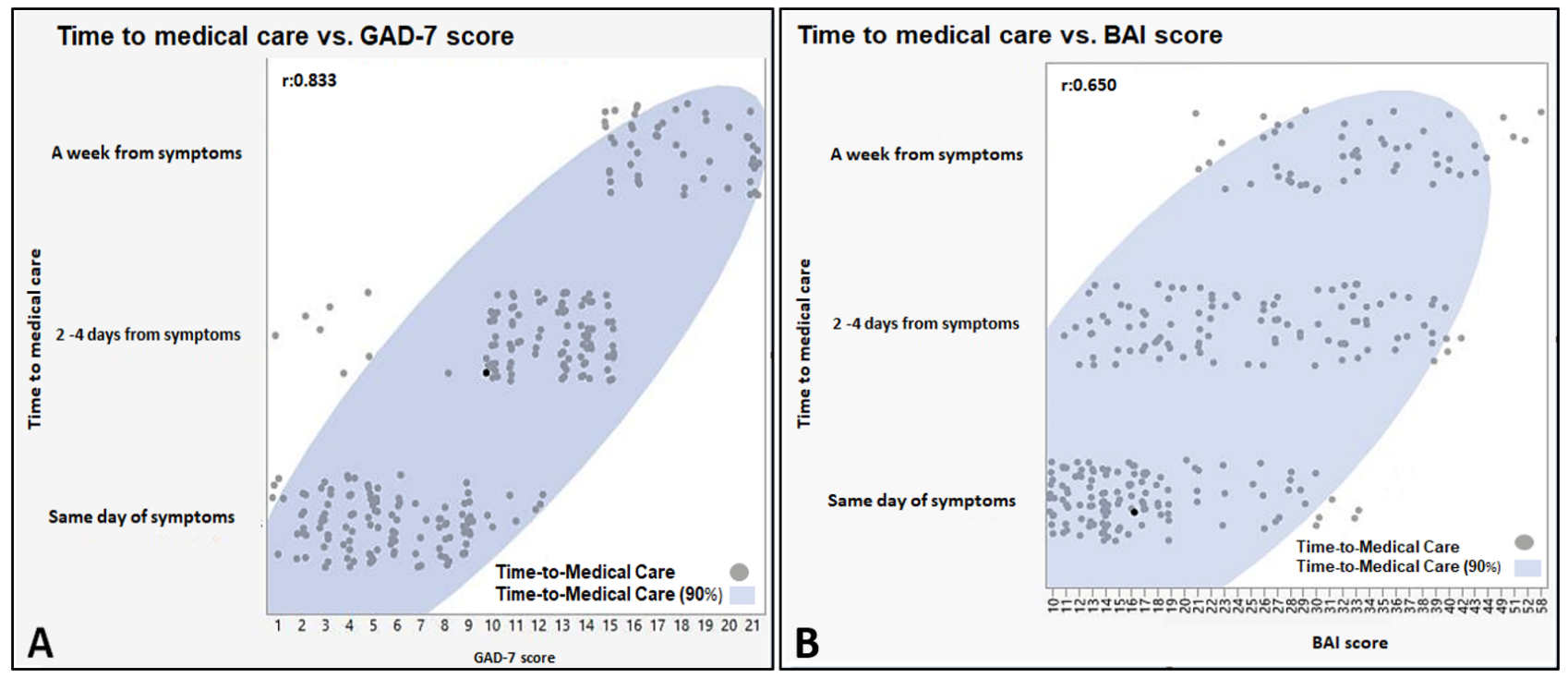

Fig. 3. Correlation between time to seek medical care and anxiety. (A) Anxiety assessed by GAD-7 questionnaire; (B) anxiety assessed by the BAI (B) questionnaire.

\section{Discussion}

Our study demonstrated a disturbingly high level of anxiety among non-COVID patients who sought medical care during the outbreak in Israel and was more pronounced in the elderly population. The normal fear of cardiovascular disease could explain the strong and positive correlation of age with high anxiety levels, yet we believe that the high mortality rate reported from the COVID infection in the elderly population had a major impact.
The high prevalence of myocardial injury in HAL patients strengthens the widely known notion that anxiety levels usually accommodate a real physical condition. Moreover, we could see that more coronary catheterization was performed on HAL patients than LAL patients. These procedural rates are consistent with the more impressive risk factors and clinical presentation of HAL compared to LAL patients as demonstrated in Tables 1,2. Nevertheless, the absence of anxiety does not directly correlate with the prevalence of coronary artery disease, nor its severity, as 

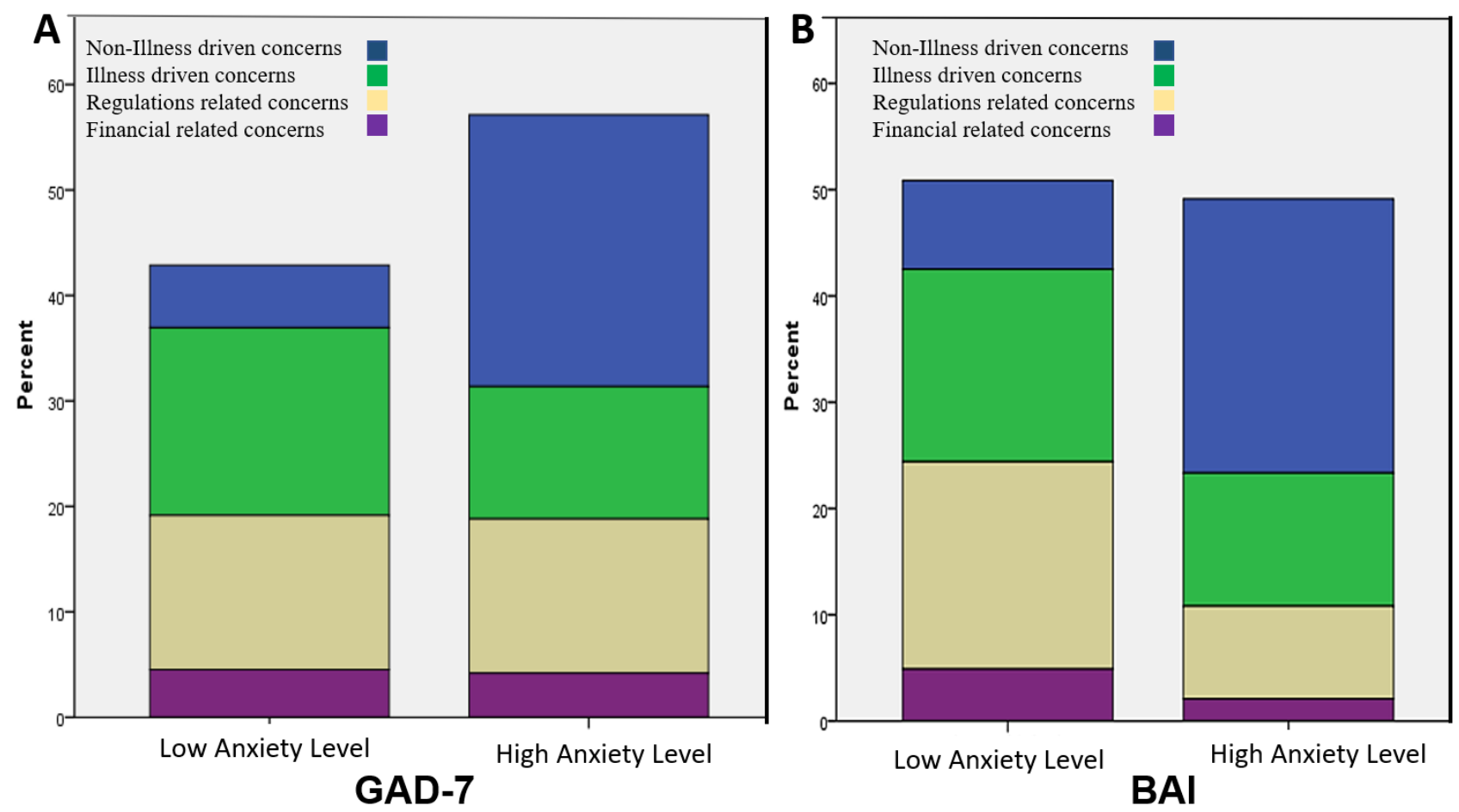

Fig. 4. Decision-driven concerns based on the DM-19 questionnaire: restriction-related concerns (blue), illness driven (green), financial-driven (grey), and anxiety-driven (purple) concerns. (A) Anxiety level according to GAD-7. questionnaire; (B) anxiety level according to BAI questionnaire.

seen in the high rate of coronary artery disease among LAL patients.

Our study shows a positive correlation between anxiety level and the decision to seek medical care of nonCOVID patients, which eventually results in deferring serious medical care. This observation could provide an additional explanation for the higher incidence of out-ofhospital cardiac arrest and higher mortality rate reported during the outbreak [32-38]. Our data is consistent with retrospective observational studies conducted outside of Israel $[39,40]$. In March of 2020 in Austria and Italy, investigators demonstrated a dramatic decline in the admission and treatment rates across all subtypes of acute coronary syndromes. Meanwhile, deaths related to acute coronary syndromes tripled. Similarly, in the US, the rate of STEMIrelated catherization lab activations declined precipitously.

\section{Application and limitation of the study}

We believe that Health organizations services should be aware of the high level of anxiety of non-COVID patients and its impact on seeking medical care. In doing so, the healthcare field can adapt the necessary provisions to inform medical care during a global pandemic. One important factor is the education of policymakers, legislative parties, and media outlets. These groups play a large role in modern-day public perception, particularly with the ongoing pandemic's social, health, and economic uncertainty [41]. Using these influencing bodies, public campaigns can help encourage people to promptly seek health care upon noticing signs or symptoms unrelated to COVID-19 infection [42-46].

Additionally, recommendations to current health policy guidelines may also influence the population in seeking medical care. One solution is instituting more frequent virtual primary consultations. Gaining increasing popularity in the last decade, virtual visits help avoid physical proximity to providers and other patients, thereby reducing the risk of contracting COVID-19 [47-59]. Moreover, providers can use the virtual platform to maintain care for their patients, namely vulnerable individuals more likely to defer care during the pandemic. This includes those with a severe, known disease requiring close monitoring, the elderly, and psychiatric patients. Virtual visits can also be a means to distribute short questionnaires to address lingering health concerns, assess anxiety levels, and help determine appropriate timing for an in-person or additional virtual consultation. Lastly, healthcare providers can be educated, encouraged, and incentivized to offer more comprehensive and strong emotional support to non-infected patients.

With regards to limitations, the study lacks a strict causal design, making some of the inferences and analyses difficult to interpret. Specifically, we did not have data to demonstrate our patient population's healthcare-seeking behavior before the pandemic. In large part, this was due to the abrupt onset of the pandemic and its ongoing status. Therefore, it would be insightful to assess further changes 
in anxiety level and healthcare-seeking behavior in light of updated news and regulations. Additionally, a comparator group of patients who did not enter the emergency department with health problems was not available, further limiting this analysis's findings and causal nature.

Decision-making is a complicated field in psychology with limited assessment tools. The rapid nature of the pandemic requires us to design a new, concise (as the clinical scenario indicated) and multilingual survey to reflect the aim of the study best. Therefore, the DM-19 questionnaire could not be validated before the study. Moreover, we focused on the main observations and showed the raw data from the surveys instead of implying multiple analytic methods. Finally, self-assessment questionnaires are inherently subjective and do not account for variability in patient responses. This is particularly relevant in the context of our study where we asked patients to quantify their anxiety. For instance, it is possible that the highly anxious patients are more likely to report a falsely higher score on the DM-19 questionnaire compared to those with lesser levels of anxiety [60-72].

Our study represents a single center's experience in the northeast of the country and therefore does not truly represent the entire population. However, the pandemic did not have geographical diversity, and the national regulations applied to the entire population. Therefore, we believe that geographical variation did not play a major role in decision-making during that period. Nonetheless, it is imperative to determine whether our findings are pertinent across different regions in the world. Differences in government response, containment, and politicization of the pandemic likely affect patient perception of the pandemic and therefore their routine behavior including decisions to seek medical care [73-80]. Additionally, our study was conducted prior to the distribution of the coronavirus vaccine. Future studies may demonstrate a shift in patient perception and anxiety given increased vaccine's protective effects [81-84].

\section{Conclusions}

Nearly half of patients admitted to the emergency department during the COVID-19 outbreak display high anxiety level. Old, married, and unemployed patients with multiple cardiovascular comorbidities and a history of anxiety, depression, or psychiatric disorder demonstrated significant HAL.

While patients with HAL presented with more objective evidence of myocardial injury, they were less frequently diagnosed with coronary artery disease via coronary catheterization.

The decision to seek medical care has a positive and significant correlation with anxiety levels. HAL patients reported seeking medical care 2-4 days from symptom onset, which was significantly higher than LAL patients. HAL patients were also more concerned about non-illness-derived anxiety than LAL patients, while the latter was more concerned about an illness-derived concern and losing financial support.

A future study involving patients in different geographic regions across different pandemic peaks at various vaccination stages may give us more information on human behaviors in seeking medical care during the pandemic.

\section{Author contributions}

OK, SAR, ER, YT, KZ, WS, DI and EM designed the research study. SAR, MB, MS, AS, KZ, WS, DI and EM performed the research. OK, MB, MS, AS, and EM analyzed the data. OK, RN, VP, EN, YT, ER analyzed the data. $\mathrm{OK}, \mathrm{RN}, \mathrm{EN}, \mathrm{VP}$ assist in revision the manuscript. All authors contributed to editorial changes in the manuscript. All authors read and approved the final manuscript.

\section{Ethics approval and consent to participate}

The Ethics Committee approved the study of the hospital following the Helsinki Convention (Approval No. EMC-20-0057). All subjects gave their informed consent for inclusion before they participated in the study.

\section{Acknowledgment}

Not applicable.

\section{Funding}

This research received no external funding.

\section{Conflict of interest}

The authors declare no conflict of interest.

\section{Supplementary material}

Supplementary material associated with this article can be found, in the online version, at https://www.imrpre ss.com/journal/RCM/23/2/10.31083/j.rcm2302050.

\section{References}

[1] Daly M, Robinson E. Anxiety reported by US adults in 2019 and during the 2020 COVID-19 pandemic: Population-based evidence from two nationally representative samples. Journal of Affective Disorders. 2021; 286: 296-300.

[2] Ambelu A, Birhanu Z, Yitayih Y, Kebede Y, Mecha M, Abafita $\mathrm{J}$, et al. Psychological distress during the COVID-19 pandemic in Ethiopia: an online cross-sectional study to identify the need for equal attention of intervention. Annals of General Psychiatry. 2021; 20: 22.

[3] Liu Y, Li P, Lv Y, Hou X, Rao Q, Tan J, et al. Public awareness and anxiety during COVID-19 epidemic in China: A crosssectional study. Comprehensive Psychiatry. 2021; 107: 152235.

[4] Wong LP, Alias H, Md Fuzi AA, Omar IS, Mohamad Nor A, Tan MP, et al. Escalating progression of mental health disorders during the COVID-19 pandemic: Evidence from a nationwide survey. PLoS ONE. 2021; 16: e0248916.

[5] Danet Danet A. Psychological impact of COVID-19 pandemic in Western frontline healthcare professionals. A systematic review. Medicina Clinica. 2021; 156: 449-458. 
[6] Doo EY, Kim M, Lee S, Lee SY, Lee KY. Influence of anxiety and resilience on depression among hospital nurses: A comparison of nurses working with confirmed and suspected patients in the COVID-19 and non-COVID-19 units. Journal of Clinical Nursing. 2021; 30: 1990-2000.

[7] Roca M, Gili M, Garcia-Campayo J, García-Toro M. Economic crisis and mental health in Spain. The Lancet. 2013; 382: $1977-$ 1978.

[8] Boursier V, Gioia F, Musetti A, Schimmenti A. Facing Loneliness and Anxiety During the COVID-19 Isolation: The Role of Excessive Social Media Use in a Sample of Italian Adults. Frontiers in Psychiatry. 2020; 11: 586222.

[9] Salari N, Hosseinian-Far A, Jalali R, Vaisi-Raygani A, Rasoulpoor S, Mohammadi M, et al. Prevalence of stress, anxiety, depression among the general population during the COVID-19 pandemic: a systematic review and meta-analysis. Globalization and Health. 2020; 16: 57.

[10] Beuke CJ, Fischer R, McDowall J. Anxiety and depression: why and how to measure their separate effects. Clinical Psychology Review. 2003; 23: 831-848.

[11] de Visser L, van der Knaap LJ, van de Loo AJAE, van der Weerd CMM, Ohl F, van den Bos R. Trait anxiety affects decisionmaking differently in healthy men and women: towards genderspecific endophenotypes of anxiety. Neuropsychologia. 2010; 48: $1598-1606$.

[12] Wu T, Luo Y, Broster LS, Gu R, Luo Y. The impact of anxiety on social decision-making: behavioral and electrodermal findings. Social Neuroscience. 2013; 8: 11-21.

[13] Bishop SJ, Gagne C. Anxiety, Depression, and Decision Making: a Computational Perspective. Annual Review of Neuroscience. 2018; 41: 371-388.

[14] Tiffen J, Corbridge SJ, Slimmer L. Enhancing clinical decision making: development of a contiguous definition and conceptual framework. Journal of Professional Nursing. 2014; 30: 399405.

[15] Moazzami B, Razavi-Khorasani N, Dooghaie Moghadam A, Farokhi E, Rezaei N. COVID-19 and telemedicine: Immediate action required for maintaining healthcare providers well-being. Journal of Clinical Virology. 2020; 126: 104345.

[16] Shyrock T. COVID-19 Raises Ethical Dilemmas for Many Physicians. 2020. Available at: https: //www.medicaleconomics.com/news/covid-19-raises-ethic al-dilemmas-many-physicians (Accessed: 17 April 2020).

[17] Lipley N. Covid-19: Not a 'Mental Health Crisis', Healthcare Experts Warn. 2020. Available at: https: //rcni.com/nursing-standard/newsroom/news/COVID-19-n ot-a-mental-health-crisis-healthcare-experts-warn-159611 (Accessed: 17 April 2020).

[18] Goulia P, Mantas C, Dimitroula D, Mantis D, Hyphantis T. General hospital staff worries, perceived sufficiency of information and associated psychological distress during the $\mathrm{A} / \mathrm{H} 1 \mathrm{~N} 1$ influenza pandemic. BMC Infectious Diseases. 2010; 10: 322.

[19] Chan AOM, Huak CY. Psychological impact of the 2003 severe acute respiratory syndrome outbreak on health care workers in a medium size regional general hospital in Singapore. Occupational Medicine. 2004; 54: 190-196.

[20] McAlonan GM, Lee AM, Cheung V, Cheung C, Tsang KWT, Sham PC, et al. Immediate and sustained psychological impact of an emerging infectious disease outbreak on health care workers. Canadian Journal of Psychiatry. Revue Canadienne De Psychiatrie. 2007; 52: 241-247.

[21] Patel RS, Bachu R, Adikey A, Malik M, Shah M. Factors Related to Physician Burnout and its Consequences: A Review. Behavioral Sciences. 2018; 8: 98.

[22] Lai J, Ma S, Wang Y, Cai Z, Hu J, Wei N, et al. Factors Associated with Mental Health Outcomes among Health Care Workers
Exposed to Coronavirus Disease 2019. JAMA Network Open. 2020; 3: e203976.

[23] Spitzer RL, Kroenke K, Williams JBW, Löwe B. A brief measure for assessing generalized anxiety disorder: the GAD-7. Archives of Internal Medicine. 2006; 166: 1092-1097.

[24] Ruiz MA, Zamorano E, García-Campayo J, Pardo A, Freire O, Rejas J. Validity of the GAD-7 scale as an outcome measure of disability in patients with generalized anxiety disorders in primary care. Journal of Affective Disorders. 2011; 128: 277-286.

[25] Beck AT, Epstein N, Brown G, Steer RA. An inventory for measuring clinical anxiety: psychometric properties. Journal of Consulting and Clinical Psychology. 1988; 56: 893-897.

[26] Osman A, Hoffman J, Barrios FX, Kopper BA, Breitenstein JL, Hahn SK. Factor structure, reliability, and validity of the Beck Anxiety Inventory in adolescent psychiatric inpatients. Journal of Clinical Psychology. 2002; 58: 443-456.

[27] Ryan TJ, Faxon DP, Gunnar RM, Kennedy JW, King SB, Loop FD, et al. Guidelines for percutaneous transluminal coronary angioplasty. A report of the American College of Cardiology/American Heart Association Task Force on Assessment of Diagnostic and Therapeutic Cardiovascular Procedures (Subcommittee on Percutaneous Transluminal Coronary Angioplasty). Circulation. 1988; 78: 486-502.

[28] Giordano A, Biondi-Zoccai G, Frati G, Bartorelli AL. Management of Structural Heart Disease and Acute Coronary Syndromes in the COVID-19 Pandemic. Current Atherosclerosis Reports. 2020; 22: 29.

[29] Biondi Zoccai G, Landoni G, Carnevale R, Cavarretta E, Sciarretta S, Frati G. SARS-CoV-2 and COVID-19: facing the pandemic together as citizens and cardiovascular practitioners. Minerva Cardioangiologica. 2020; 68: 61-64.

[30] Driggin E, Madhavan MV, Bikdeli B, Chuich T, Laracy J, Biondi-Zoccai G, et al. Cardiovascular Considerations for Patients, Health Care Workers, and Health Systems During the COVID-19 Pandemic. Journal of the American College of Cardiology. 2020; 75: 2352-2371.

[31] Perek B, Olasinska-Wisniewska A, Misterski M, Puslecki M, Grygier M, Buczkowski $\mathrm{P}$, et al. How the COVID-19 pandemic changed treatment of severe aortic stenosis: a single cardiac center experience. Journal of Thoracic Disease. 2021; 13: 906-917.

[32] Płońska-Gościniak E, Suwalski P, Bartuś S, Kukulski T, Komar M, Wojakowski W, et al. Management of valvular and structural heart diseases during the coronavirus disease 2019 pandemic: an expert opinion of the Working Group on Valvular Heart Diseases, the Working Group on Cardiac Surgery, and the Association of Cardiovascular Interventions of the Polish Cardiac Society. Kardiologia Polska. 2020; 78: 498-507.

[33] Fudulu DP, Angelini GD. Cardiac surgery in the time of the coronavirus. Journal of Cardiac Surgery. 2020; 35: 1177-1179.

[34] Kang S, Jung SI. Age-Related Morbidity and Mortality among Patients with COVID-19. Infection \& Chemotherapy. 2020; 52: 154.

[35] Thakkar S, Arora S, Kumar A, Jaswaney R, Faisaluddin M, Ammad Ud Din M, et al. A Systematic Review of the Cardiovascular Manifestations and Outcomes in the Setting of Coronavirus19 Disease. Clinical Medicine Insights Cardiology. 2020; 14: 117954682097719.

[36] Rattka M, Dreyhaupt J, Winsauer C, Stuhler L, Baumhardt M, Thiessen K, et al. Effect of the COVID-19 pandemic on mortality of patients with STEMI: a systematic review and metaanalysis. Heart. 2020; 107: 482-487.

[37] Jain V, Gupta K, Bhatia K, Bansal A, Arora S, Khandelwal AK, et al. Management of STEMI during the COVID-19 pandemic: Lessons learned in 2020 to prepare for 2021. Trends in Cardiovascular Medicine. 2021; 31: 135-140.

[38] Natarajan MK, Wijeysundera HC, Oakes G, Cantor WJ, Miner 
SES, Welsford M, et al. Early Observations during the COVID19 Pandemic in Cardiac Catheterization Procedures for STElevation Myocardial Infarction across Ontario. CJC Open. 2020; 2: 678-683.

[39] Roy-Byrne PP, Wagner A. Primary care perspectives on generalized anxiety disorder. The Journal of Clinical Psychiatry. 2004; 65: 20-26.

[40] Wittchen HU, Zhao S, Kessler RC, Eaton WW. DSM-III-R generalized anxiety disorder in the National Comorbidity Survey. Archives of General Psychiatry. 1994; 51: 355-364.

[41] Kessler RC, Brandenburg N, Lane M, Roy-Byrne P, Stang PD, Stein DJ, et al. Rethinking the duration requirement for generalized anxiety disorder: evidence from the National Comorbidity Survey Replication. Psychological Medicine. 2005; 35: 10731082.

[42] Wortham JM, Lee JT, Althomsons S, Latash J. Characteristics of Persons who Died with COVID-19-United States, February 12 -may 18,2020 . Morbidity and Mortality Weekly Report. 2020; 69: 923-929.

[43] Zhou RA, Baicker K, Taubman S, Finkelstein AN. The uninsured do not use the emergency department more- they use other care less. Health Affairs (Project Hope). 2017; 36: 21152122.

[44] Moazzami B, Razavi-Khorasani N, Dooghaie Moghadam A, Farokhi E, Rezaei N. COVID-19 and telemedicine: Immediate action required for maintaining healthcare providers well-being. Journal of Clinical Virology. 2020; 126: 104345.

[45] Shyrock T. COVID-19 Raises Ethical Dilemmas for Many Physicians. 2020. Available at: https: //www.medicaleconomics.com/news/covid-19-raises-ethic al-dilemmas-many-physicians (Accessed: 17 April 2020).

[46] Lipley N. Covid-19: Not a 'Mental Health Crisis', Healthcare Experts Warn. 2020. Available at: https: //rcni.com/nursing-standard/newsroom/news/COVID-19-n ot-a-mental-health-crisis-healthcare-experts-warn-159611 (Accessed: 17 April 2020).

[47] Zhang W, Wang K, Yin L, Zhao W, Xue Q, Peng M, et al. Mental Health and Psychosocial Problems of Medical Health Workers during the COVID-19 Epidemic in China. Psychotherapy and Psychosomatics. 2020; 89: 242-250.

[48] Tan BYQ, Chew NWS, Lee GKH, Jing M, Goh Y, Yeo LLL, et al. Psychological Impact of the COVID-19 Pandemic on Health Care Workers in Singapore. Annals of Internal Medicine. 2020; 173: 317-320.

[49] Maunder RG, Leszcz M, Savage D, Adam MA, Peladeau N, Romano D, et al. Applying the lessons of SARS to pandemic influenza: an evidence-based approach to mitigating the stress experienced by healthcare workers. Canadian Journal of Public Health. 2008; 99: 486-488.

[50] Byers SK. Organizational stress: implications for health promotion managers. American Journal of Health Promotion. 1987; 2: 21-27.

[51] Dong E, Du H, Gardner L. An interactive web-based dashboard to track COVID-19 in real time. The Lancet Infectious Diseases. 2020; 20: 533-534.

[52] Johns Hopkins University \& Medicine, Johns Hopkins University (JHU). Coronavirus resource center: COVID-19 dashboard by the center for systems science and engineering (CSSE). 2020. Available at: https://coronavirus.jhu.edu/map.html (Accessed: 29 June 2020).

[53] Centers for Disease Control and Prevention. Coronavirus Disease 2019 (COVID-19): cases in the U.S. 2020. Available at: https://www.cdc.gov/coronavirus/2019-ncov/cases-updates /cases-in-us.html (Accessed: 29 June 2020).

[54] Centers for Disease Control and Prevention. Coronavirus Dease 2019 (COVID-19): COVID-19 in Racial and Ethnic Minority Groups. 2020. Available at: https://www.cdc.gov/coronavirus/2019-ncov/need-extra-p recautions/racial-ethnic-minorities.html (Accessed: 18 May 2020).

[55] Centers for Disease Control and Prevention. Estimated Influenza Illnesses, Medical Visits, Hospitalizations, and Deaths in the United States - 2018-2019 influenza season. 2020. Available at: https://www.cdc.gov/flu/about/burden/2018-2019.html (Accessed: 18 May 2020).

[56] Litman L, Robinson J, Abberbock T. CloudResearch.com: A versatile crowdsourcing data aquisition platform for the behavioral sciences. Behavior Research Methods. 2017; 49: 433-442.

[57] U.S. Census Bureau. Age and sex composition in the United States: 2019. 2019. Available at: https://www.census.gov/data/tables/2019/demo/age-and-s ex/2019-age-sex-composition.html (Accessed: 23 June 2020).

[58] U.S. Department of Health and Human Services. Regional Offices. 2014. Available at: https://www.hhs.gov/about/agencies/i ea/regional-offices/index.html (Accessed: 15 May 2020).

[59] Smith GCS, Seaman SR, Wood AM, Royston P, White IR. Correcting for optimistic prediction in small data sets. American Journal of Epidemiology. 2014; 180: 318-324.

[60] Schaffer DeRoo S, Pudalov NJ, Fu LY. Planning for a COVID19 Vaccination Program. Journal of the American Medical Association. 2020; 323: 2458-2459.

[61] Yancy CW. COVID-19 and African Americans. Journal of the American Medical Association. 2020; 323: 1891-1892.

[62] Owen WF, Carmona R, Pomeroy C. Failing another National Stress Test on Health Disparities. Journal of the American Medical Association. 2020; 323: 1905-1906.

[63] U.S. Bureau of Labor Statistics. Unemployment rates and earnings by educational attainment. 2019. Available at: https://ww w.bls.gov/emp/chart-unemployment-earnings-education.html (Accessed: 20 May 2020)

[64] McEachan RRC, Conner M, Taylor NJ, Lawton RJ. Prospective prediction of health-related behaviors with the theory of planned behavior: A meta-analysis. Health Psychology Review. 2011; 5: 97-144.

[65] Chen RT, Orenstein WA. Epidemiological methods in immunization programs. Epidemiologic Reviews. 1996; 18: 99-117.

[66] Sanche S, Lin YT, Romero-Severson E, Hengartner N, Ke R. High contagiousness and rapid spread of severe acute respiratory syndrom coronavirus 2. Emerging Infectious Diseases. 2020; 26: 1470.

[67] Kata A. A postmodern Pandora's box: anti-vaccination misinformation on the internet. Vaccine. 2010; 28: 1709-1716.

[68] Larson HJ. Blocking information on COVID-19 can fuel the spread of misinformation. Nature. 2020; 580: 306.

[69] Benecke O, DeYoung SE. Anti-Vaccine Decision-Making and Measles Resurgence in the United States. Global Pediatric Health. 2019; 6: 2333794X19862949.

[70] Johnson NF, Velasquez N, Restrepo NJ. The online competition between pro- and anti-vaccination views. Nature. 2020;582: 230-233.

[71] Greenberg N, Docherty M, Gnanapragasam S, Wessely S. Managing mental health challenges faced by healthcare workers during covid-19 pandemic. British Medical Journal. 2020; 368: $\mathrm{m} 1211$.

[72] Shanafelt T, Ripp J, Trockel M. Understanding and Addressing Sources of Anxiety among Health Care Professionals during the COVID-19 Pandemic. Journal of the American Medical Association. 2020; 323: 2133-2134.

[73] Zhou T, Huang S, Cheng J, Xiao Y. The Distance Teaching Practice of Combined Mode of Massive Open Online Course Micro-Video for Interns in Emergency Department during the COVID-19 Epidemic Period. Telemedicine and E-Health. 2020; 
26: 584-588.

[74] Chick RC, Clifton GT, Peace KM, Propper BW, Hale DF, Alseidi AA, Vreeland TJ. Using Technology to Maintain the Education of Residents during the COVID-Pandemic. Journal of Surgical Education. 2020; 77: 729-732.

[75] Stevenson J. COVID-19 Information Overload Leads to Simple but Unhelpful Choices. 2020. Available at: https://www.city.ac.uk/news/2020/april/covid-19-information -overload-leads-to-simple-but-unhelpful-choices (Accessed: 17 April 2020)

[76] Blake H, Somerset S, Evans C. Development and Fidelity Testing of the Test@Work Digital Toolkit for Employers on Workplace Health Checks and Opt-In HIV Testing. International Journal of Environmental Research and Public Health. 2020; 17: 379.

[77] Linnan L, Steckler A. Process Evaluation for Public Health Interventions and Research: An Overview. Jossey-Bass: San Francisco, CA, USA. 2002.

[78] Murray E, Hekler EB, Andersson G, Collins LM, Doherty A, Hollis C, et al. Evaluating Digital Health Interventions: Key Questions and Approaches. American Journal of Preventive Medicine. 2016; 51: 843-851.

[79] Ruiz JG, Candler C, Teasdale TA. Peer reviewing e-learning: opportunities, challenges, and solutions. Academic Medicine.
2007; 82: 503-507.

[80] Blake H, Bermingham F. Psychological wellbeing for healthcare workers: Mitigating the impact of COVID-19. 2020. Available at: https:/www.nottingham.ac.uk/toolkits/play_22794 (Accessed: 17 April 2020).

[81] Hoffmann TC, Glasziou PP, Boutron I, Milne R, Perera R, Moher $\mathrm{D}$, et al. Better reporting of interventions: template for intervention description and replication (TIDieR) checklist and guide. British Medical Journal. 2014; 348: g1687. (In German)

[82] Walsh EE, Frenck RW, Falsey AR, Kitchin N, Absalon J, Gurtman A, et al. Safety and Immunogenicity of Two RNA-Based Covid-19 Vaccine Candidates. The New England Journal of Medicine. 2020; 383: 2439-2450.

[83] Metzler B, Siostrzonek P, Binder RK, Bauer A, Reinstadler SJ. Decline of acute coronary syndrome admissions in Austria since the outbreak of COVID-19: the pandemic response causes cardiac collateral damage. European Heart Journal. 2020; 41: $1852-1853$.

[84] Garcia S, Albaghdadi MS, Meraj PM, Schmidt C, Garberich $\mathrm{R}$, Jaffer FA, et al. Reduction in ST-segment elevation cardiac catheterization laboratory activations in the United States during COVID-19 pandemic. Journal of the American College of Cardiology. 2020; 75: 2871-2872. 